\title{
Effect of Physical Treatment on the Properties of Composites Based on Natural Fibres
}

\author{
Ivana Schwarzova ${ }^{1}$, Nadezda Stevulova ${ }^{2}$, Eva Terpakova ${ }^{3}$, Jozef Junak ${ }^{4}$ \\ ${ }^{1-4}$ Technical University of Kosice
}

\begin{abstract}
Due to the low density and high porosity of the hemp hurds, the combination of hemp and binder creates a building material with good thermal and acoustic insulation properties. Today hemp hurds can be used in high-quality products such as hemp concrete, fibre board and composites.

In this paper, the attention is given to the study of the properties of lightweight composites based on modified hemp hurds as filler and MgO-cement as binder. The cohesion of the filler and of the binder is an important factor in the development of mechanical properties. The impact of ultrasonic treatment of hemp hurds and its cooking in water for $1 \mathrm{~h}$ on the physical and mechanical properties (compressive strength, density, water absorbability, thermal conductivity) of the composites hardened in indoor condition was studied. The observation is also focused on the influence of the hemp hurds length. The durability of produced composites was studied under different conditions.
\end{abstract}

Keywords - Composite materials, hemp fibres, physical treatment, testing properties

\section{INTRODUCTION}

One of the possible ways to achieve sustainable development in construction industry is to use easily renewable raw material resources instead of the limited and finite material resources. Over the past few years, interest in the utilization of lignocellulosic biomass in the form of natural fibres as organic filler in composite materials for sustainable building constructions is steadily increasing [1]. Lignocellulosic materials as one of the group of fast growing plants are characterized by many excellent physical and mechanical properties which predetermine the use of plant fibres in building materials (biocomposites) prepared with inorganic matrix [2,3].

Traditional building materials such as concrete are increasingly being replaced by advanced composite materials, e.g. fibre reinforced polymers and fibre reinforced cement. It is expected that fibre/polymer composites will expand their usage in the near future due to the advantages offered by these materials, i.e. adequate strength, low weight and low maintenance cost.

Plant fibres such as hemp, jute, kenaf, sisal, bamboo and other fibres have been studied for their mechanical properties and their potential contributions in composite materials. These natural fibre reinforced composites are finding their way in the construction industry. The application of natural fibres as reinforcement in composite materials is constantly in development. The drawbacks of its mechanical properties are being studied to maximise its full potential as an alternative to synthetic fibres [4].
Nowadays, attention is paid to the technical hemp (Cannabis Sativa L.) for its building application.

The hemp as a building composite component is rapidly renewable, carbon-negative, non-toxic, mildew-resistant, pestfree and flame-resistant. Technical hemp is becoming a major focus of green housing because of its energy-efficient cultivation as well as its health benefits. Excellent physical and mechanical properties of hemp predetermine its use in building materials (biocomposites) prepared with inorganic matrix [1].

In the use of hemp fibres, the major problem is heterogeneity of this material. In general, celluloses in natural fibres are identified as a main structural component of the fibre which is present mainly in crystalline phase. Further components of plant fibres are hemicelluloses, lignin and pectin. Hemicellulose and lignin present mostly in amorphous state play an important role in controlling its properties [5].

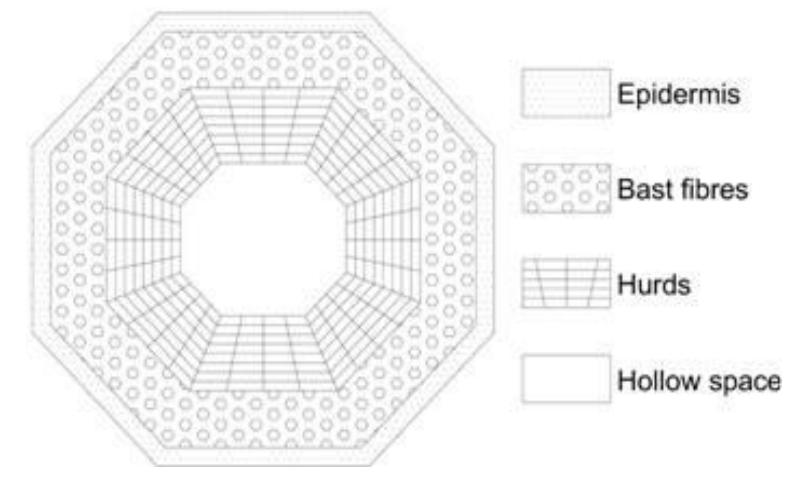

Fig. 1. Cross section of hemp stem.

The technical hemp (Cannabis Sativa L.) is the source of two types of fibres (Fig. 1); bast fibres (used mainly in the paper and textile industries) and woody fibres called hurds (in construction industry). The properties of hemp fibres depend on the fibre chemical composition. The bast fibres contain more amounts of cellulose compared to the hemp hurds. On the contrary, contents of hemicellulose and lignin as amorphous substances are higher in hurds [6].

Hemp hurds are used in preparation of building materials, mainly in the production of thermal insulation composites due to their porous structure.

The properties of biocomposites depend on the chemical composition and structure of hemp material, matrix properties as well as good adhesion in the fibres - matrix interface. Therefore, the surface treatment procedure of the hemp fibres is used for the improvement of the adhesion in the fibres matrix interface [4]. 
The most interesting aspect about hemp fibres is their positive environmental impact and their rapid renewability. The use of cellulosic fibres as reinforcement in composites is influenced by the shape, properties and the portion of fibres. Key problem for successful application of hemp hurds as reinforcement in biocomposites is its heterogeneity and related incompatibility with matrix. The incompatibility between natural fibres and matrix leads to low interface strength in comparison to glass or carbon fibre composites. The major cause of this drawback is the presence of hydroxyl and other polar groups in natural fibres which makes them hydrophilic in nature. Many research projects have been devoted to the study of enhancement of the adhesion at the fibres-matrix (polymer or mineral) interface, using of various methods for modification of the surface fibres and matrix [7-9]. Optimizing the adhesion of fibres consists in their pre-treatment leading to removing impurities and amorphous components (pectin, lignin, hemicellulose) and separation of bundles of fibres in the fibrils [9].

In this paper, the attention is given to physical modification of technical hemp and to the use of modified hemp hurds as organic filler in composites as well as testing of physical and mechanical properties of lightweight composites with nonconventional binder $\mathrm{MgO}$-cement.

\section{MATERIAL AND METHODS}

\section{A. Material}

In this experimental study, the technical hemp hurds (coming from Netherlands company Hempflax) were used as a filler in composite materials.

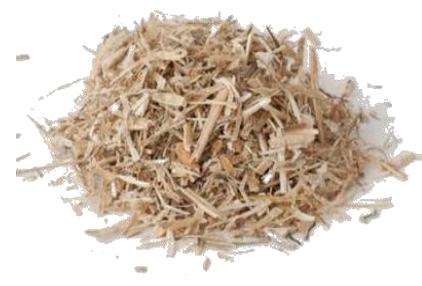

Fig. 2. Hemp hurds slices.

This material (Fig. 2) contains more hurds material than bast fibres. The used hemp material was polydispersive with a wide particle length distribution $(8-0.063 \mathrm{~mm})$. The mean particle length of hemp hurds was $1.94 \mathrm{~mm}$. Density of hemp material was $117.5 \mathrm{~kg} \cdot \mathrm{m}^{-3}$. A milled and oven-dried sample was used for the determination of chemical composition of hemp hurds. The chemical composition of used hemp material is shown in Table I.
TABLE I

ESTIMATED CHEMICAL COMPOSITION OF HEMP HURDS

\begin{tabular}{|l|l|c|}
\hline \multicolumn{2}{|l|}{ Percentage of components of hemp hurds } & {$[\%]$} \\
\hline \multirow{3}{*}{ Holocellulose } & Cellulose & 42.6 \\
\cline { 2 - 3 } & Hemicellulose & 29.1 \\
\hline \multirow{3}{*}{} & Lignin & 23.7 \\
\cline { 2 - 3 } & Toluene - ethanol extract & 2.8 \\
\cline { 2 - 3 } & Ash & 1.8 \\
\hline
\end{tabular}

The content of holocellulose was determined by using the modified method according to Wisea. The quantitative determination of cellulose was performed by the KürschnerHoffer nitration method. The content of acid-insoluble (Klason) lignin was carried out by two-step hydrolysis of polysaccharides portion in sulphuric acid. Total ash content (mineral substances) was measured by combustion of sample and subsequent annealing. Toluene-ethanol extract containing mainly extractable waxes, fats, resins as well as water extractives was obtained by extraction in a Soxhlet apparatus for $6-8 \mathrm{~h}$ at $90^{\circ} \mathrm{C}$.

For the preparation of composites based on hemp hurds, alternative binder $\mathrm{MgO}$-cement consisting of caustic magnesite obtained by low temperature decomposition of natural magnesite (CCM 85, SMZ a.s. Jelsava, Slovakia), silica sand (Sastin, Slovakia) with the dominant component of $\mathrm{SiO}_{2}(95-98 \%)$ and sodium hydrogen carbonate (p.a) were used. $\mathrm{MgO}$ was milled in order to reduce its particle size. Dry milling was carried out in laboratory vibratory mill VM 4 for 5 $\min [10]$.

\section{B. Modification of fibres}

The physical modification of dried hemp hurds was made in two ways.

At first, physical modification of hemp hurds surface was realized by its thermotreatment in hot water $\left(100^{\circ} \mathrm{C}\right)$ for $1 \mathrm{~h}$. $100 \mathrm{~g}$ of hemp hurds was added to 1 litre of distilled water.

The second treatment procedure was performed by using ultrasound. An ultrasonic bath TESON 10 (Tesla, Slovakia) was used for ultrasonic cleaning process of hemp hurds. This device of 10 litres tub capacity is mono-frequency with low voltage $(220 \mathrm{~V}, 50 \mathrm{~Hz}, 650 \mathrm{~W}$ of power output). The experiment was performed using samples (approximately $1000 \mathrm{~g}$ of dried hemp hurds) immerged in 10 litres of distilled water during 60 minutes sonication.

After physical treatments, hemp hurds samples were dried at $80^{\circ} \mathrm{C}$ and their surface was obviously distraught and shredded. 


\section{Preparation of composite samples}

Experimental mixtures prepared according to the recipe published in work [11] consisted of 40 vol. \% of hemp hurds (unmodified as a referential material and modified), 29 vol. \% of $\mathrm{MgO}$-cement and 31 vol. \% of water. The components of mixture were homogenized in the dry form and then mixed with water addition. Standard steel cube forms with dimensions 100x100x100 mm were used for preparation of samples in accordance with the standard STN EN 206-1/A1 [12]. The specimens of lightweight composite materials were cured for 2 days in an indoor climate and then were removed from the forms. Curing was continued under laboratory conditions during 7, 28, 60 and 90 days.

\section{Testing methods}

The density, compressive strength, thermal conductivity coefficient and water absorbability were measured on hardened composite specimens under laboratory conditions. Density was determined in accordance with standard STN EN 12390-7 [13]. Compressive strengths of all lightweight composites were determined using the instrument ADR 2000 (ELE International Ltd., United Kingdom). The thermal conductivity coefficient of samples as the main parameter of heat transport was measured by the commercial device ISOMET 104 (Applied Precision Ltd., Germany). The measurement is based on the analysis of the temperature response of the studied material to heat flow impulses. The heat flow is induced by electrical heating using a resistor heater having direct thermal contact with the surface of the sample. Water absorption (after one hour) was specified in accordance with the standard STN EN 12087/A1 [14].

\section{RESULTS AND DISCUSSION}

The following values are the average of three measurements.

The density values of prepared composite samples, shown in Table II, were ranged from 980 to $1,230 \mathrm{~kg} \cdot \mathrm{m}^{-3}$ which places them into the category of lightweight composites. The measured values of density are comparable with building materials, such as aerated autoclaved concrete (800$\left.1,200 \mathrm{~kg} \cdot \mathrm{m}^{-3}\right)[12]$.

TABLE II

VALUES OF COMPOSITES DENSITY DEPENDING ON TIME OF HARDENING

VALUES OF COMPOSITES DENSITY DEPENDING ON TIME OF HARDENING
\begin{tabular}{|l|c|c|c|}
\hline $\begin{array}{l}\text { Time of } \\
\text { hardening }\end{array}$ & 28 days & 60 days & 90 days \\
\cline { 1 - 2 } $\begin{array}{l}\text { Density of } \\
\text { sample }\left[\mathrm{kg} \cdot \mathrm{m}^{-3}\right]\end{array}$ & 1,070 & 1,085 & 1,120 \\
\cline { 1 - 2 } Referential & 980 & 1,030 & 1,070 \\
\hline Boiled & 1,160 & 1,190 & 1,230 \\
\hline $\begin{array}{l}\text { Ultrasonic } \\
\text { treated }\end{array}$ & & & \\
\hline
\end{tabular}


mean particle length of hemp hurds slices. This result is in accordance with published data [16], where mechanical properties of hemp hurds composites with binder based on hydrated lime with 5\% Portland cement addition are depended on the length of hemp fibres. The best effect on mechanical parameter of composites had ultrasonic treatment of hemp hurds. Higher values of compressive strength are connected with better alignment of hurds slices in volume of inorganic matrix of the composites and with the formation of a denser composite structure.

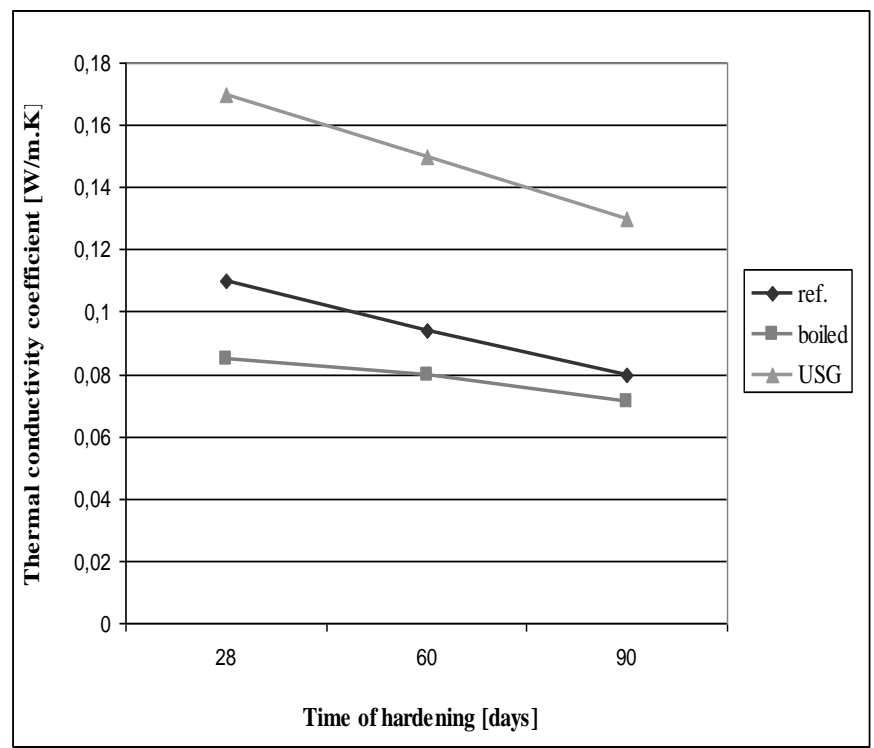

Fig. 5. Dependence of composites thermal conductivity coefficient on the time of hardening.

Lightweight composites are used as thermal insulation in buildings; this is assessed by measuring their coefficient of thermal conductivity.

The measured values of thermal conductivity coefficient of composites with unmodified and modified hemp hurds (after time of hardening 28, 60 and 90 days), shown in Fig. 5, were varied from 0.071 to $0.17 \mathrm{~W} \cdot \mathrm{m}^{-1} \cdot \mathrm{K}^{-1}$. The best values were recorded for the composite samples based on modified (hydrothermal treated) hemp hurds. These values were lower than values of thermal conductivity of hemp composites with lime binder [17]. As it can be seen in Fig. 5, the values of thermal conductivity coefficient decrease with increasing hardening time. All measured values of the prepared bicomoposites samples are in the range acceptable for the thermal insulating materials.

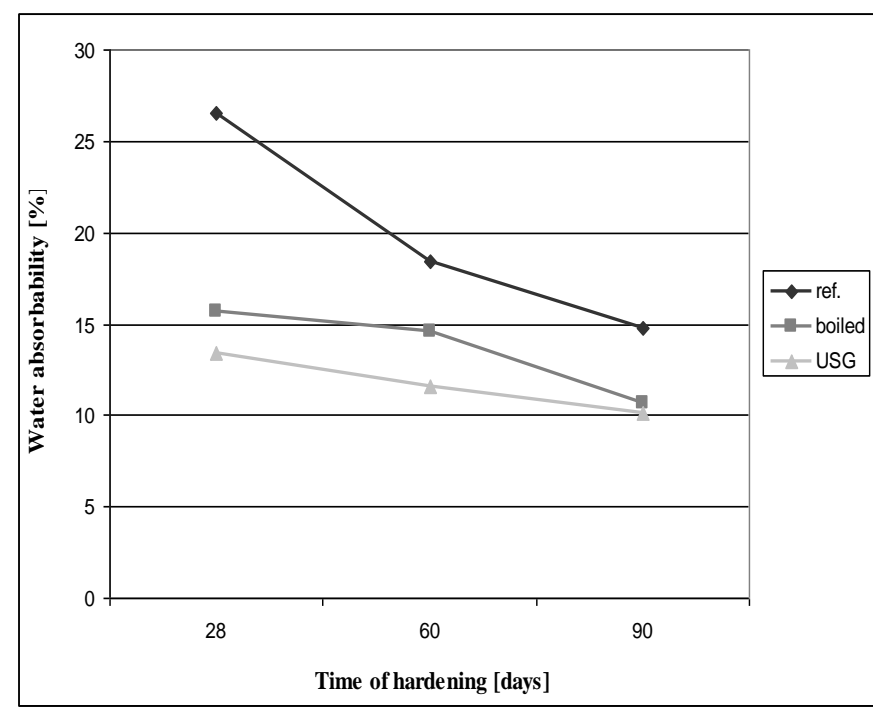

Fig. 6. Dependence of water absorbability of prepared composite materials on time of hardening.

The water absorption values of the prepared composite samples, shown in Fig. 6, present decreasing water absorbability of composites based on hemp hurds with increasing time of hardening. Values of water absorption are in the range $14.8-26 \%$ for biocomposites based on unmodified hemp hurds and in the range $10.3-16.1 \%$ for composite samples prepared from modified hemp hurds. Water absorbability in hardened composites is dependent on the internal porous system. The results confirmed that the absorbability is decreasing over the time that may indicate the fact that hydration products of binder gradually fill the vacant interior spaces in the composite.

As Fig. 6 shows, the specimens with modified hemp hurds have observably lower values of water absorption than composites based on unmodified fibres. It means that the physical modification of hemp hurds reduced water absorption of the lightweight composites based on cellulosic fibres. According to literature data [18] and our results, the physical treatment changes structural and surface properties of the fibres but it does not extensively change their chemical composition (Table III).

TABLE III

VALUES OF COMPOSITES DENSITY DEPENDING ON TIME OF HARDENING

\begin{tabular}{|l|c|c|c|}
\hline $\begin{array}{l}\text { Percentage of components of hemp hurds } \\
{[\%]}\end{array}$ & ref. & boiled & USG \\
\hline Cellulose & 42.6 & 43.4 & 44.4 \\
\hline Holocellulose & 77.3 & 77.2 & 77.7 \\
\hline Lignin & 23.7 & 23.3 & 24.6 \\
\hline Toluene - ethanol extract & 2.8 & 2.4 & 2.6 \\
\hline Ash & 1.8 & 1.0 & 1.2 \\
\hline
\end{tabular}




\section{CONCLUSIONS}

This paper deals with the application of hemp hurds as organic filler in unmodified and modified form in building materials. Physical modification of hemp hurds by hydrothermal treatment (cooking in hot water) and ultrasonic treatment were used as the methods for removal of organic and inorganic loosely bound contaminants from surfaces of hemp hurds. The results show that modification of hemp hurds has an impact on some physical properties and strength parameter of hardened biocomposites prepared with $\mathrm{MgO}$ cement as an alternative binder.

The values of compressive strength, thermal conductivity coefficient and water absorbability of hemp composites depend on the time of hardening as well as on the surface modification of hemp hurds slices.

The values of all of prepared composite samples predetermine this material to its use as a thermal insulation. Performance is positive in terms of future use of lightweight lignocellulosic composites. The composites on the fast natural renewable material source are potentially contributing to sustainable development due to their environmental benefits.

More investigations are needed to understand and explain the influence of physical modification of natural fibres and the use of alternative binder in nature composites structure.

\section{ACKNOWLEDGEMENTS}

The authors are grateful to the Slovak Grant Agency for financial support of the project VEGA1/0277/15.

\section{REFERENCES}

[1] O. Faruk, A.K. Bledzki, H.P. Fink and M. Sain, "Biocomposites reinforced with natural fibres 2000 - 2010," Progress in Polymer Science, vol. 37, 2012, pp. 1552-1596. http://dx.doi.org/10.1016/j.progpolymsci.2012.04.003

[2] A.K. Bledzki and J. Gassan, "Composites reinforced with cellulose based fibres," Progress in Polymer Science, vol. 24, 1999, pp. 221-274. http://dx.doi.org/10.1016/S0079-6700(98)00018-5

[3] P.B. de Brujin, K.H. Jeppsson, K. Sandin and Ch. Nilsson, "Mechanical properties of lime-hemp concrete containing shives and fibres," Biosystems Engineering., vol. 103, 2009, pp. 474-479. http://dx.doi.org/10.1016/j.biosystemseng.2009.02.005
[4] Z.N. Azwa, B.F. Yousif, A.C. Manalo and W. Karunasena, "A review on the degradability of polymeric composites based on natural fibres", Materials and Design, vol 47, 2013, pp. 424-442. http://dx.doi.org/10.1016/i.matdes.2012.11.025

[5] M.S. Sreekala, M.G. Kumaran, S. Joseph and M. Jacob, "Oil Palm fibre reinforced phenol formaldehyde composites: Influence of fibre surface modifications on the mechanical performance", Applied Composite Materials, vol 7, 2000, pp. 295-329. http://dx.doi.org/10.1023/A:1026534006291

[6] E. Gumuskaya, M. Usta and M. Balaban, "Carbohydrate components and crystalline structure of organosolv hemp (Cannabis sativa L.) bast fibers pulp", Bioresource Technology, vol 98, 2007, pp. 491-497. http://dx.doi.org/10.1016/j.biortech.2006.02.031

[7] N.E. Zafeiropoulos, "Interface Engineering of Natural Fibre Composites for Maximum Performance", Woodhead Publishing in Materials, 2011. http://dx.doi.org/10.1533/9780857092281

[8] R. Kumar, S. Obrai and A. Sharma "Chemical modifications of natural fiber for composite material", Der Chemica Sinica, vol. 2, 2011, pp. 219-228.

[9] B.A. Thomsen, A. Thygesen., V. Bohn, K.V. Nielsen, B. Pallesen and M.S. Jorgensen, "Effect of chemical-physical pre-treatment processes on hemp fibres for reinforcement of composites and for textiles", Industrial Crops and Products, vol. 24, 2006, pp. 113-118. http://dx.doi.org/10.1016/j.indcrop.2005.10.003

[10] L. Kidalova, "Determination of selected characteristics in hemp concrete", In Young Scientist: 3rd PhD. Student Conference of Civil Engineering and Architecture, Kosice: Technical university of Kosice, Faculty of Civil Engineering, 2011, pp. 1-6.

[11] J. Bydzovsky, "Utilization of rapidly renewable raw materials in building materials", Proceedings of the 12th International Scientific Conference, Brno, Czech Republic, 2009, Brno:Technical University, pp. 43-46.

[12] STN EN 206-1/A1 Concrete, Part 1: Specification, performance, production and conformity, 2009.

[13] STN EN 12390-7 Testing hardened concrete, Part 7: Density of hardened concrete, 2011.

[14] STN EN 12087/A1 Thermal insulating products for building applications, 2007.

[15] N. Stevulova, E. Terpakova, J. Cigasova, J. Junak and L. Kidalova, "Chemically Treated Hemp Shives as a Suitable Organic Filler for Lightweight Composites Preparing", Procedia Engineering: 20th International Congress of Chemical and Process Engineering CHISA 2012, Prague, Czech republic, vol. 42, 2012, pp. 1035-1042.

[16] R. Brencis, J. Skujans, U. Iljins, I. Ziemelis and O. Osits, "Research on foam gypsum with hemp fibrous reinforcement", Chemical Engineering Transactions, vol. 25, 2011, pp. 159-164

[17] J. Cigasova, N. Stevulova and J. Junak, "Influence of binder nature on properties of lightweight composites based on hemp hurds", International Journal of Modern Manufacturing Technologies, vol. 5, 2013, pp. 27-31.

[18] S. Renouard, CH. Hano, J. Doussot, J.-P. Blondeau, and E. Lainé, "Characterization of ultrasonic impact on coir, flax and hemp fibers", Materials Letters, DOI: http://dx.doi.org/10.1016/j.matlet (accessed 18 may 2014). 